\title{
Rapid Analysis of 129 in Natural Water Samples Using Accelerator Mass Spectrometry
}

Zhang, Mengting; Hou, Xiaolin; Zhang, Zhiyong; Zhang, Luyuan; Chen, Ning; Fang, Miao

Published in:

Atomic Spectroscopy

Link to article, DOI:

10.46770/AS.2021.071

Publication date:

2021

Document Version

Publisher's PDF, also known as Version of record

Link back to DTU Orbit

Citation (APA):
Zhang, M., Hou, X., Zhang, Z., Zhang, L., Chen, N., \& Fang, M. (2021). Rapid Analysis of ${ }^{129}$ I in Natural Water Samples Using Accelerator Mass Spectrometry. Atomic Spectroscopy, 42(4), 190-196.

https://doi.org/10.46770/AS.2021.071

\section{General rights}

Copyright and moral rights for the publications made accessible in the public portal are retained by the authors and/or other copyright owners and it is a condition of accessing publications that users recognise and abide by the legal requirements associated with these rights.

- Users may download and print one copy of any publication from the public portal for the purpose of private study or research.

- You may not further distribute the material or use it for any profit-making activity or commercial gain

- You may freely distribute the URL identifying the publication in the public portal 


\title{
Atomic pectroscopy .

\section{Rapid Analysis of ${ }^{129}$ I in Natural Water Samples Using Accelerator Mass Spectrometry}

\author{
Mengting Zhang, ${ }^{\text {a,e }}$ Xiaolin Hou, ${ }^{\text {a,c,e, }, *}$ Zhiyong Zhang,,${ }^{\text {b, }}$ Luyuan Zhang, ${ }^{\text {a,d }}$ Ning Chen, ${ }^{\text {a }}$ and Miao \\ Fang a,e \\ ${ }^{a}$ State Key Laboratory of Loess and Quaternary Geology, Shaanxi Key Laboratory of Accelerator Mass Spectrometry Technology and Application, Xi'an, \\ AMS Center of IEECAS, Institute of Earth Environment, Chinese Academy of Sciences, Xi' an 710061, P.R. China \\ ${ }^{\mathrm{b}}$ Institute of High Energy Physics, Chinese Academy of Sciences, Beijing 100049, P. R. China \\ ${ }^{\mathrm{c}}$ Department of Environmental Engineering, Technical University of Denmark, Ris $\varnothing$ Campus, Roskilde 4000, Denmark \\ ${ }^{d}$ Open Studio for Oceanic-Continental Climate and Environment Changes, Pilot National Laboratory for Marine Science and Technology (Qingdao), \\ Qingdao 266061, P.R. China \\ ${ }^{\mathrm{e}}$ University of Chinese Academy of Sciences, Beijing 100049, P.R. China
}

Received: March 15, 2021; Revised: April 01, 2021; Accepted: April 01, 2021; Available online: April 01, 2021.

DOI: 10.46770/AS.2021.071

ABSTRACT: A rapid and simple co-precipitation method for iodine separation from natural samples was developed for determination of ${ }^{129} \mathrm{I}$ using accelerator mass spectrometry (AMS). The method includes three steps, i.e. decomposition of organic iodine, iodine separation and target preparation using co-precipitation, and sensitive measurement of ${ }^{129} \mathrm{I} /{ }^{127} \mathrm{I}$ ratio using AMS. The recovery of iodine was higher than $90 \%$ for most natural water samples in the decomposition step using $\mathrm{K}_{2} \mathrm{~S}_{2} \mathrm{O}_{8}$. Iodine in the digested sample was then co-precipitated as $\mathrm{AgI}-\mathrm{AgCl}-\mathrm{Ag}_{2} \mathrm{SO}_{3}-\mathrm{Ag}_{2} \mathrm{SO}_{4}$ with a typical recovery of $95-98 \%$. It was observed that addition of $0.2 \mathrm{mg}{ }^{127} \mathrm{I}$ carrier can significantly improve the measurement uncertainty of low-level ${ }^{129} \mathrm{I}$ samples by enhancing iodine ion current. The overall recovery of iodine in the entire procedure was higher than $80 \%$, and a detection limit of $1.0 \times 10^{5}$ atoms (or $\left.2.2 \times 10^{-17} \mathrm{~g}\right)$ for ${ }^{129} \mathrm{I}$ was achieved. The developed method was validated by certified reference material (IAEA-418) and five types of natural water samples in comparison with results using the conventional solvent extraction method. Analytical results showed good agreement with the reference values for all samples, confirming the reliability of the developed method. The simple operation, with no need for organic solvent and small amount of iodine carrier addition make the developed method suitable for rapid and reliable determination of low level ${ }^{129} \mathrm{I}$ in natural water samples.

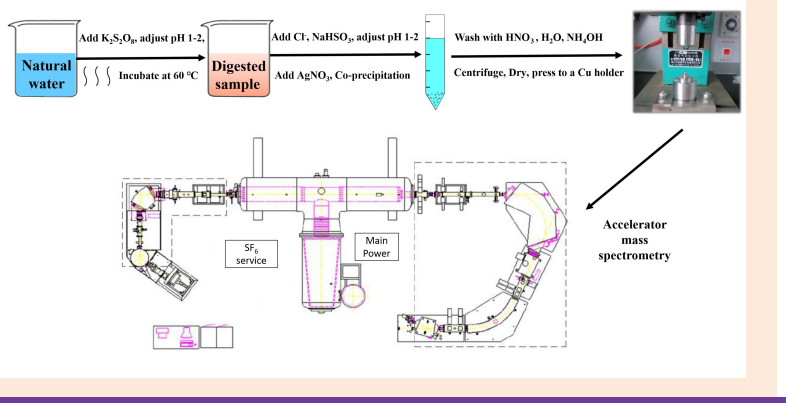

\section{INTRODUCTION}

As a long-lived (15.7 Ma) radioisotope of iodine, ${ }^{129} \mathrm{I}$ is naturally produced mainly through spallation reaction of atmospheric Xe with cosmic rays, the spontaneous fission of ${ }^{238} \mathrm{U}$, and thermal neutron-induced fission of ${ }^{235} U$ in the earth's crust. ${ }^{1,2}$ The natural abundance of ${ }^{129} \mathrm{I}$ in the hydrosphere was reported to be about $1.5 \times 10^{-12}\left({ }^{129} \mathrm{I} /{ }^{127} \mathrm{I}\right)$ based on the measurement of marine sediment samples. ${ }^{3-5}$ However, the ${ }^{129} \mathrm{I} /{ }^{127} \mathrm{I}$ atomic ratios have been significantly increased to more than $10^{-10}$ due to anthropogenic input including nuclear weapons tests, spent fuel reprocessing plants and nuclear accidents, 5,6 even up to $10^{-4}$ in the heavily contaminated area. ${ }^{7-11}$ Iodine is a water-soluble and biophilic element, it mainly occurs as iodide, iodate and various organic associated forms in the nature. Due to its unique sources, chemical properties and long half-life, the ${ }^{129} \mathrm{I}$ has attracted high interests of geologists, chemists and environmental scientists for its application in dating of geological events, ${ }^{12}$ environmental tracing, ${ }^{13}$ geochemical cycle of iodine, ${ }^{14,15}$ and safety assessment of nuclear facilities. ${ }^{16}$ These works require a reliable, sensitive and rapid analytical method for determination of ${ }^{129} \mathrm{I}$ in different types 
of samples including water samples. Solvent extraction is the most commonly used method for separation of iodine from water samples. ${ }^{3,17}$ This method was used to directly separate ${ }^{129}$ I from samples with high iodine concentration, or from samples spiked with $0.5-2 \mathrm{mg}$ of stable iodine carrier before extraction. The major limitation of this method is that iodine concentration in the samples has to be sufficiently high (>0.5 $\mathrm{mg} / \mathrm{L})$ to obtain a high chemical yield of ${ }^{129} \mathrm{I}(>50 \%) .{ }^{18} \mathrm{In}$ addition, the water volume is limited to a few liters in this method due to difficulty in practical operation. For analysis of a large volume of water samples, anion exchange chromatography was used to pre-concentrate iodine, which is time-consuming since the flow rate needs to be controlled within $1 \mathrm{~mL} / \mathrm{min}$. Meanwhile, this method is not well suitable for determine ultra-low level ${ }^{129} \mathrm{I}$ in water sample, because ${ }^{127} \mathrm{I}$ carrier $(0.5-2 \mathrm{mg})$ which contains some amount of ${ }^{129} \mathrm{I}$ has to be added to the sample in the solvent extraction operation after the chromatographic separation. The often-used iodine reagent of low ${ }^{129}$ I content was prepared from old brine, such as that supplied by Woodward Iodine Corporation, the measured ${ }^{129} \mathrm{I} /{ }^{127} \mathrm{I}$ ratios normally range from 0.5 to $2.0 \times 10^{-13},{ }^{19-21}$ although the lowest value of $0.2 \times 10^{-13}$ has been reported. ${ }^{22-24}$ This small amount of ${ }^{129} \mathrm{I}$ in iodine carrier might be negligible for the analysis of samples with ${ }^{129} \mathrm{I} /{ }^{127} \mathrm{I}>10^{-10}$. However, the contribution of ${ }^{129} \mathrm{I}$ in the carrier makes it difficult to determine ultralow level ${ }^{129} \mathrm{I}$, which is often required in geological, environmental and geochemical studies. In addition, the method of solvent extraction with $\mathrm{CCl}_{4}$ or $\mathrm{CHCl}_{3}$ generates toxic organic waste, which is not environment friendly.

A co-precipitation method has been proposed to separate iodine from seawaters for measurement of ${ }^{129} \mathrm{I}$ using accelerator mass spectrometry, ${ }^{25-27}$ which can avoid the utilization of organic solvent and large amount of ${ }^{127}$ I carrier. This work aims to further extend this method, with focus on rapid separation and sensitive determination of ${ }^{129} \mathrm{I}$ in natural waters (lake, river, rain, and ground water).

\section{EXPERIMENTAL}

Samples and chemicals. Four fresh water samples from Xi'an, China in 2019 and one seawater from the East China Sea were collected. The collected water was stored in PE containers. A rain water sample was collected on the roof of Xi'an Accelerator Mass Spectrometry Center $\left(34^{\circ} 13.42^{\prime} \mathrm{N}, 109^{\circ} 0.01^{\prime} \mathrm{E}\right)$ on 19th May, 2019. The river water samples were first kept still for overnight to allow for the settlement of suspending materials (mud/sand), and the supernatants were collected. All water samples were filtered through $0.45 \mu \mathrm{m}$ membrane within 2 days after collection.

NaI gamma detector (Model FJ-2021, Xi'an Nuclear Instrument factory, Xi'an, China) was used for measuring ${ }^{125} \mathrm{I}$ to monitor chemical recovery of iodide during separation. A pneumatic press
(Model J1303/GBWN, Jiangsu Audt riveting \& pressure equipment Co., LTD, China) was used to target preparation. An inductively coupled plasma mass spectrometry (ICP-MS) (Agilent 8800 ) was used to measure stable ${ }^{127}$ I. A 3 MV Tandetron AMS (HEVV, The Netherlands) in the Xi' an AMS Center was used for measure ${ }^{129} \mathrm{I} /{ }^{127} \mathrm{I}$ atomic ratio in the prepared targets.

All chemical reagents used were of analytical grade reagent, including $\mathrm{K}_{2} \mathrm{~S}_{2} \mathrm{O}_{8}, \mathrm{NaHSO}_{3}, \mathrm{HNO}_{3}, \mathrm{NaNO}_{2}$, and $\mathrm{AgNO}_{3}$. All solutions were prepared using deionized water of $18.2 \mathrm{M} \Omega \cdot \mathrm{cm}$, produced by Cascada ${ }^{\mathrm{TM}}$ Lab Water System (Pall Life Sciences, USA). Iodine crystal with a ${ }^{129} \mathrm{I} /{ }^{127} \mathrm{I}$ atomic ratio of $2 \times 10^{-14}$ was provided by Woodward Inc. (USA), and dissolved in $0.40 \mathrm{~mol} / \mathrm{L}$ $\mathrm{NaOH}-0.05 \mathrm{~mol} / \mathrm{L} \mathrm{NaHSO}_{3}$ solution. ${ }^{129} \mathrm{I}$ standard solution (NISTSRM-4949C) from the National Institute of Standard and Technology (Gaithersburg, MD, USA) was used to prepare ${ }^{129} \mathrm{I}$ standard by mixing with certain amount of ${ }^{127} \mathrm{I}$ (Woodward Inc. USA). $\mathrm{Na}^{125}$ I solution (Chengdu Gaotong isotope corporation, China) as the tracer solution was diluted in $0.001 \mathrm{~mol} / \mathrm{L} \mathrm{NaOH}$. Niobium powders (325 mesh) was purchased from Alfa Aesar Company (Ward Hill, MA, USA).

Separation of iodine from environmental samples. Filtered fresh water or seawater $(0.6 \mathrm{~L})$ was weighed to a beaker. $0.2 \mathrm{mg}$ of ${ }^{127} \mathrm{I}$ carrier and $5.0 \mathrm{kBq}$ of ${ }^{125} \mathrm{I}$ tracer solution were spiked. $18 \mathrm{~g}$ of $\mathrm{K}_{2} \mathrm{~S}_{2} \mathrm{O}_{8}$ was added to sample to a final concentration of $30 \mathrm{~g} / \mathrm{L}$, and $3.0 \mathrm{~mol} / \mathrm{L} \mathrm{HNO}_{3}$ was add to adjust $\mathrm{pH} 1-2$. The prepared water sample was heated on a hotplate and incubated at $60{ }^{\circ} \mathrm{C}$ for $20 \mathrm{~h}$, in order to decompose organic substances and convert organic iodine into inorganic forms. ${ }^{28}$ After cooled to room temperature, $0.5 \mathrm{~mL}$ of $2.0 \mathrm{~mol} / \mathrm{L} \mathrm{NaHSO}_{3}$ and $3.0 \mathrm{~mol} / \mathrm{L} \mathrm{HNO}_{3}$ were added to adjust pH1-2 to reduce all inorganic iodine to iodide. After addition of $0.5 \mathrm{mg}$ chloride (as $\mathrm{NaCl}$, to fresh water samples), 30

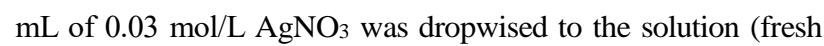
water and seawater) under stirring to form $\mathrm{AgI}-\mathrm{AgCl}-\mathrm{Ag}_{2} \mathrm{SO}_{3}-$ $\mathrm{Ag}_{2} \mathrm{SO}_{4}$ coprecipitate. ${ }^{125} \mathrm{I}$ in the supernatant $(1 \mathrm{~mL})$ was measured using a gamma detector, and the recovery of iodine in this step was measured by comparing the ${ }^{125}$ I activity in the supernatant with ${ }^{125} \mathrm{I}$ standard spiked to the sample. The supernatant was decanted, and the precipitate was separated by centrifuge. The separated precipitated was sequentially rinsed with $\mathrm{HNO}_{3}, \mathrm{H}_{2} \mathrm{O}$, and diluted $\mathrm{NH}_{4} \mathrm{OH}$ (5-10\%) (only for seawater) to remove $\mathrm{Ag}_{2} \mathrm{SO}_{3}$ and most of $\mathrm{AgCl}$ respectively, until 1-3 $\mathrm{mg}$ of precipitate was obtained. The separated $\mathrm{AgI}-\mathrm{AgCl}$ coprecipitate was dried in an oven at $60-70{ }^{\circ} \mathrm{C}$, ground to a fine power, and mixed with five times by mass of niobium power, which was finally pressed into a copper holder using a pneumatic press. Procedure blank was prepared using the same procedure but without sample. A schematic diagram of the separation procedure is shown in Fig. 1.

Measurement of ${ }^{129} \mathrm{I}$ and ${ }^{127} \mathrm{I}$. Atomic ratios of ${ }^{129} \mathrm{I} /{ }^{127} \mathrm{I}$ in the prepared $\mathrm{AgI}-\mathrm{AgCl}$ targets were measured by AMS using 3MV Tandem AMS system (HVEE) in the Xi' an AMS center. I' ions sputtered from the ion source was accelerated, and then stripped 


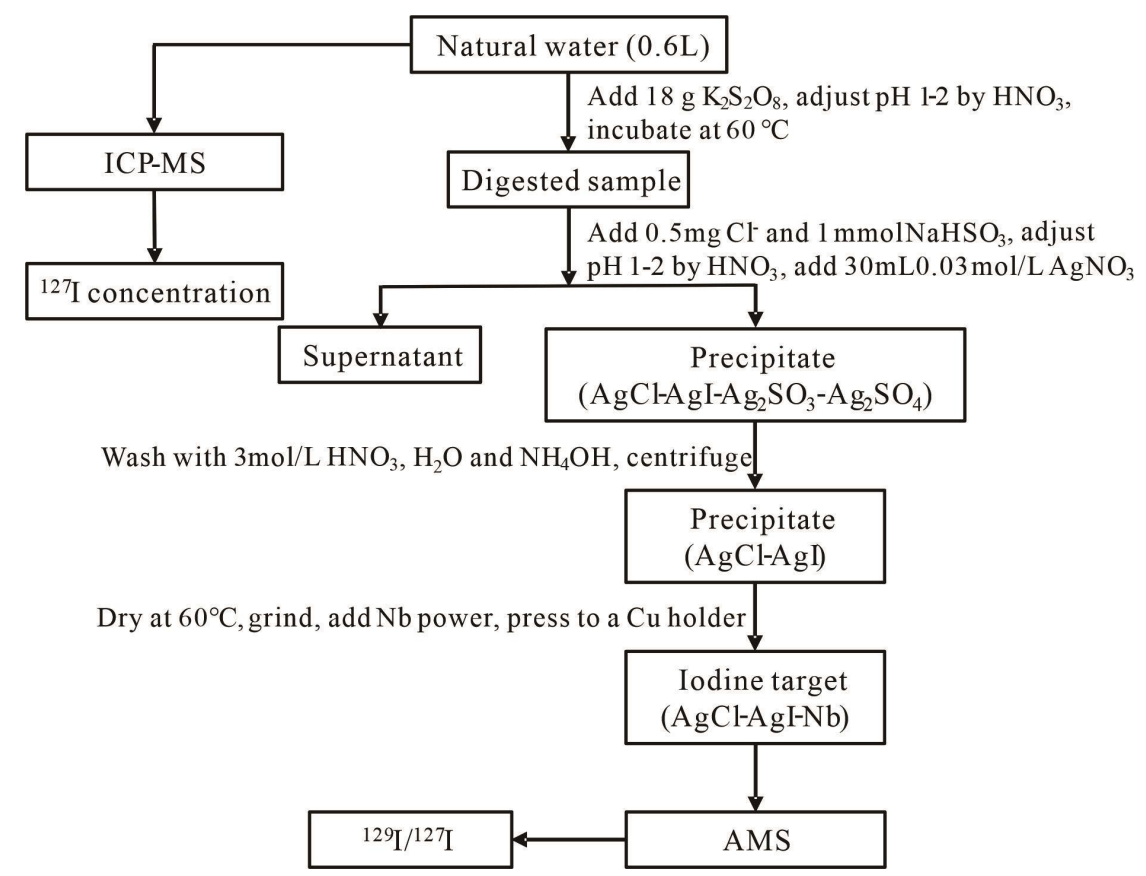

Fig. 1 Schematic diagram of procedure for separation of total iodine from natural water.

in the stripper with Ar gas, $\mathrm{I}^{5+}$ was chosen, and ${ }^{127} \mathrm{I}^{5+}$ was measured as charges (current) using a Faraday cup and ${ }^{129} \mathrm{I}^{5+}$ was measured using a gas ionization detector. All samples were measured for 6 cycles and 5 min per sample in each cycle. A detailed description of AMS system and measurement of ${ }^{129} \mathrm{I}$ has been reported elsewhere. $^{29}$

Stable iodine $\left({ }^{127} \mathrm{I}\right)$ in fresh water samples and seawater were measured using ICP-MS (Agilent 8800) after dilution for 2 times for fresh water and 20 times for seawater using $1 \% \mathrm{NH}_{4} \mathrm{OH} . \mathrm{Cs}^{+}$ solution was spiked to a concentration of $2 \mathrm{ng} / \mathrm{mL}$ as internal standard. The detection limit of the method for ${ }^{127} \mathrm{I}$ was estimated as 3 times of blank to be $0.02 \mathrm{ng} / \mathrm{mL}$.

\section{RESULTS AND DISCUSSION}

Decomposition of organic iodine in natural waters. For fresh water, such as lake, river and rain water, large fraction of iodine occurs in organic form, ${ }^{30,31}$ mainly as humic substances associated iodine. In these substances, iodine is covalently bound to aromatic or phenolic groups, and difficult to be separated from matrix without decomposition of organic substances. Iodine in fresh water is normally low $(<5 \mu \mathrm{g} / \mathrm{L})$, a large volume of sample ( $>500$ $\mathrm{mL})$ is therefore needed for determination of low level ${ }^{129} \mathrm{I}$ in these samples. Decomposition by oxidation using $\mathrm{K}_{2} \mathrm{~S}_{2} \mathrm{O}_{8}$ has been proposed to release iodine from organic substance in natural water samples at a temperature higher than $40^{\circ} \mathrm{C}$ by formation of sulfate and/or hydroxyl radicals. ${ }^{28,32-34}$ Hydrogen ions might be involved in the reaction with organic matter, ${ }^{35,36}$ which makes $\mathrm{pH}$ of the

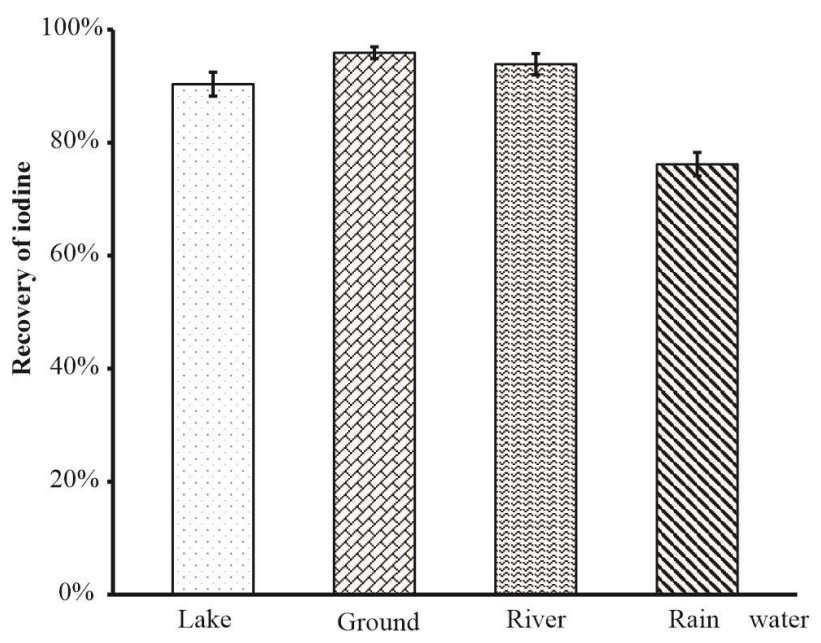

Fig. 2 Recovery of iodine in oxidizing decomposition using $\mathrm{K}_{2} \mathrm{~S}_{2} \mathrm{O}_{8}$ (at $60{ }^{\circ} \mathrm{C}$ for $20 \mathrm{~h}$ ), error bars are standard deviation of the recovery results in four parallel experiments.

solution critical for the decomposition of organic substances. It was reported that the $\mathrm{pH}<2$ is helpful for reduce the loss of iodine during decomposition of organic matter. ${ }^{28}$ Our results (Fig. 2) show that the recovery of iodine monitored by measurement of the spiked ${ }^{125}$ I is higher than $90 \%$ for most natural samples, and can reach $95.9 \pm 1.0 \%$ for ground water. This confirms that nearly all iodine is kept stable during decomposition and $\mathrm{K}_{2} \mathrm{~S}_{2} \mathrm{O}_{8}$ can successfully decompose organic iodine in all water samples.

Separation of ${ }^{129} \mathbf{I}$ from natural waters. In the $\mathrm{AgI}-\mathrm{AgCl}$ co- 
precipitation process, many precipitation reactions might be involved, the most important reactions and their solubility products $\left(\mathrm{K}_{\mathrm{sp}}\right)$ of the corresponding precipitation products are listed below:

$$
\begin{aligned}
& \mathrm{Ag}^{+}+\mathrm{I}^{-}=\mathrm{AgI} \quad \mathrm{K}_{\mathrm{sp}}(\mathrm{AgI})=8.5 \times 10^{-17} \\
& 2 \mathrm{Ag}^{+}+\mathrm{SO}_{3}{ }^{2-}=\mathrm{Ag}_{2} \mathrm{SO}_{3} \quad \mathrm{~K}_{\mathrm{sp}}\left(\mathrm{Ag}_{2} \mathrm{SO}_{3}\right)=1.5 \times 10^{-14} \\
& \mathrm{Ag}^{+}+\mathrm{Cl}^{-}=\mathrm{AgCl} \quad \mathrm{K}_{\mathrm{sp}}(\mathrm{AgCl})=1.8 \times 10^{-10} \\
& 2 \mathrm{Ag}^{+}+\mathrm{SO}_{4}{ }^{2-}=\mathrm{Ag}_{2} \mathrm{SO}_{4} \quad \mathrm{~K}_{\mathrm{sp}}\left(\mathrm{Ag}_{2} \mathrm{SO}_{4}\right)=1.7 \times 10^{-5} \\
& \mathrm{Ag}^{+}+\mathrm{IO}_{3}{ }^{-}=\mathrm{AgIO}_{3} \quad \mathrm{~K}_{\mathrm{sp}}\left(\mathrm{AgIO}_{3}\right)=3.2 \times 10^{-8}
\end{aligned}
$$

It was reported that low concentration of iodine in natural fresh water samples e.g. $0.4-15 \mu \mathrm{g} / \mathrm{L}$ in rain water and $0.1-18 \mu \mathrm{g} / \mathrm{L}$ in river water was measured.9,37 The chloride concentration in precipitation in mid-continental regions (far from oceans and other salt sources) which is less than $1 \mathrm{mg} / \mathrm{L}$, and often less than 0.1 $\mathrm{mg} / \mathrm{L},{ }^{38}$ more than thousands times lower chlorine compared to that in seawater, $19.0 \mathrm{~g} / \mathrm{L} .{ }^{39}$ Therefore, a small amount of precipitate will be formed when an excess amount of $\mathrm{AgNO}_{3}$ was added. For $1 \mathrm{~L}$ of rain water with low chloride $(<0.1 \mathrm{mg} / \mathrm{L})$, less than $0.4 \mathrm{mg}$ of co-precipitate will be formed, which makes it impossible to be effectively separated from the supernatant of the large volume of sample. Meanwhile, this cannot cope with the requirement for iodine target preparation, as nearly 1-3 mg precipitate need to be pressed into holder for AMS measurement. The amount of sulfite and chloride added as co-precipitation agents-and amount of $\mathrm{Ag}^{+}$added to form precipitation are key parameters for separation of iodine in large volume fresh water by co-precipitation.

During the decomposition of organic iodine, the iodine is converted to the iodate by oxidizing reagent $\mathrm{K}_{2} \mathrm{~S}_{2} \mathrm{O}$. Because of the relatively high solubility of $\mathrm{AgIO}_{3}\left(\mathrm{~K}_{\mathrm{sp}}=3.2 \times 10^{-8}\right)$ compared to $\mathrm{AgI}\left(\mathrm{K}_{\mathrm{sp}}=8.5 \times 10^{-17}\right)$ and a low concentration of iodine in the solution, iodate was reduced to iodide using sulfite at $\mathrm{pH}<2$ to obtain a better recovery of iodine in the co-precipitation process. Excessive amount of sulfite was added in this step to form $\mathrm{Ag}_{2} \mathrm{SO}_{3}$ precipitate. Our investigation showed that $\mathrm{Ag}_{2} \mathrm{SO}_{3}-\mathrm{AgI}$ coprecipitation significantly improved the recovery of iodine, which is attributed to the similar particle sizes of $\mathrm{AgI}$ (mainly 0.5-2.0 $\mu \mathrm{m}$ ) and $\mathrm{Ag}_{2} \mathrm{SO}_{3}$ (mainly 0.5-1.5 $\mu \mathrm{m}$ ) crystals. ${ }^{27}$ In this step, $\mathrm{NaHSO}_{3}$ not only converts the iodine to iodide, but also as a co-precipitation agent forms sufficient amount of co-precipitate with iodide. It is worth noting that sulfite compete with iodide to form precipitate with $\mathrm{Ag}^{+}$, large amount of sulfite might reduce the recovery of iodine if the amount of $\mathrm{Ag}$ added is not sufficient. In this work, 1.0 mmol sulfite (i.e. $0.5 \mathrm{~mL}$ of $2 \mathrm{~mol} / \mathrm{L} \mathrm{NaHSO}_{3}$ ) was added after digestion of the sample. The excess of $\mathrm{Ag}_{2} \mathrm{SO}_{3}$ and $\mathrm{Ag}_{2} \mathrm{SO}_{4}$ precipitate needs to be removed to reduce the total precipitate to 1$3 \mathrm{mg}$ for pressing to the target holder with niobium metal powder for AMS measurement. Meanwhile, it increases the iodine concentration in the precipitate and improve the sensitivity of AMS measurement of ${ }^{129} \mathrm{I}$. Based on the high solubility of $\mathrm{Ag}_{2} \mathrm{SO}_{3}$ and $\mathrm{Ag}_{2} \mathrm{SO}_{4}$ in acidic solution, $\mathrm{Ag}_{2} \mathrm{SO}_{3}$ and $\mathrm{Ag}_{2} \mathrm{SO}_{4}$ in the coprecipitates are easily removed by rinsing with $3 \mathrm{~mol} / \mathrm{L} \mathrm{HNO}_{3}$. In this case, almost all of $\mathrm{Ag}_{2} \mathrm{SO}_{3}$ and $\mathrm{Ag}_{2} \mathrm{SO}_{4}$ precipitates are dissolved, meanwhile, $\mathrm{AgI}$ particles are dispersed in the solution. Since the amount of $\mathrm{AgI}$ is too small $(<50 \mu \mathrm{g})$, it is suspended in the solution and could not be precipitated and handled in the following centrifugation step. Meanwhile, it is hard to get sufficient amount of co-precipitate $(<1 \mathrm{mg})$ to be handled in the target preparation due to the low concentration of iodine and

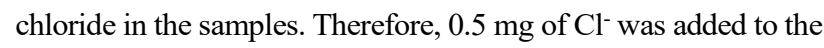
digested sample to ensure sufficient amount of precipitate for the AMS measurement of ${ }^{129} \mathrm{I}$.

In AMS measurement, ${ }^{127} \mathrm{I}$ intensity is measured by Faraday Cup, while ${ }^{129} \mathrm{I}$ is counted by ionization detector. According to the deflection of ${ }^{127}$ I measuring position by Faraday cup, terminal voltage of AMS can automatically be adjusted to take ${ }^{129} \mathrm{I}^{5+}$ through $115^{\circ}$ magnet as much as possible before reach to the detector. Therefore, the ${ }^{129} \mathrm{I}$ was adjusted according to the measured ${ }^{127}$ I ion current, and the low iodine content in the target causes a high uncertainty of ${ }^{127}$ I current, which consequently influence the stability of ${ }^{129} \mathrm{I}$ signal intensity measured in AMS. It has been observed that the measurement stability and reliability of ${ }^{129}$ I can be significantly improved when the ${ }^{127}$ I carrier increased from 0 to $0.2 \mathrm{mg} .^{40}$ Since the addition of large amount of stable iodine carrier $\left({ }^{127} \mathrm{I}\right)$ containing small amount of ${ }^{129} \mathrm{I}$ is not suitable for the determination of low-level ${ }^{129} \mathrm{I}$ in nature water, $0.2 \mathrm{mg}$ of ${ }^{127} \mathrm{I}$ carrier was added to nature water samples in this work. The ${ }^{129}$ I level in the analyzed environmental samples might vary within a few orders of magnitude, for example, the ${ }^{129} \mathrm{I} /{ }^{127} \mathrm{I}$ atomic ratios range from $10^{-12}$ in the deep-sea water or ground water samples to $10^{-8}$ in the surface water or rainwater. It is crucial that small amount of ${ }^{127}$ I carrier should be used in the analysis of ground or deep-sea water to reduce the contribution of ${ }^{129} \mathrm{I}$ in the iodine carrier to the sample.

In this work, $\mathrm{AgI}-\mathrm{AgCl}-\mathrm{Ag}_{2} \mathrm{SO}_{3}-\mathrm{Ag}_{2} \mathrm{SO}_{4}$ co-precipitation was used to separate iodine from the digested solution, and iodine recoveries of $95-98 \%$ were obtained when adding $0.5 \mathrm{mg}$ of $\mathrm{Cl}^{-}$in the solution containing $1.0 \mathrm{mmol} \mathrm{NaHSO}_{3}$. Considering the loss of iodine in the decomposition of organic iodine, an overall recovery of iodine in the entire procedure is higher than $80 \%$ for the natural water samples.

In comparison with the conventional solvent extraction method, the reported co-precipitation method for ${ }^{129}$ I determination in natural water has following advantages. (1) addition of less carrier ${ }^{127} \mathrm{I}$, which reduces the contribution of external ${ }^{129} \mathrm{I}$ and thus improves the reliability of analytical results for low-level ${ }^{129} \mathrm{I}$ samples; (2) single-step separation, which makes the separation 
Table 1 Results of ${ }^{127}$ I and ${ }^{129}$ I Signals in Procedure Blanks Using CoPrecipitation Separation and AMS Measurement

\begin{tabular}{lccc}
\hline No & $\begin{array}{c}\text { Average } \\
{ }^{127} \mathbf{I} \text { current } \\
(\mathbf{n A})\end{array}$ & $\begin{array}{c}\text { Average }{ }^{\mathbf{1 2 9}} \mathbf{I} \\
\text { count rate } \\
\text { (Counts/min) }\end{array}$ & $\begin{array}{c}\text { Measured }{ }^{{ }^{129} \mathbf{I} /{ }^{127} \mathbf{I}} \\
\text { ratio }^{\text {a }}\end{array}$ \\
\hline $\mathbf{1}$ & 184.2 & $2.9 \pm 0.5$ & $(2.28 \pm 0.32) \times 10^{-13}$ \\
$\mathbf{2}$ & 88.1 & $1.4 \pm 0.3$ & $(2.11 \pm 0.46) \times 10^{-13}$ \\
$\mathbf{3}$ & 149.3 & $2.2 \pm 0.4$ & $(2.01 \pm 0.34) \times 10^{-13}$ \\
$\mathbf{4}$ & 78.3 & $0.9 \pm 0.2$ & $(1.85 \pm 0.47) \times 10^{-13}$ \\
$\mathbf{5}$ & 164.1 & $2.3 \pm 0.4$ & $(1.81 \pm 0.25) \times 10^{-13}$ \\
$\mathbf{6}$ & 110.7 & $1.2 \pm 0.3$ & $(1.46 \pm 0.31) \times 10^{-13}$ \\
Average & & & $(1.92 \pm 0.36) \times 10^{-13}$ \\
\hline
\end{tabular}

${ }^{a}$ All data is presented as average of six measurements.

easy to operate and less time-consuming; (3) less chemicals, especially exclusion of toxic organic solvent; (4) rapid analysis, the co-precipitation does not only single step separation, but also operated for a batch of sample, such as 16 or even 24 samples, so easy to handle and analyze large number of samples.

Detection limit of analytical method for ${ }^{129}$ I. Procedure blanks were prepared using the same procedure as the sample, and the measurement results including the measured intensities of ${ }^{127} \mathrm{I}$ and ${ }^{129} \mathrm{I}$ in these blanks are presented in Table 1 . The detection limit was calculated to be $1.0 \times 10^{5}$ atoms (or $2.2 \times 10^{-17} \mathrm{~g}$ ) using three times the standard deviation of the ${ }^{129} \mathrm{I} /{ }^{127} \mathrm{I}$ ratios, sampling volume of $600 \mathrm{~mL}$ and $0.2 \mathrm{mg}{ }^{127} \mathrm{I}$ carrier. For fresh water including groundwater with iodine concentration of $1.0 \mu \mathrm{g} / \mathrm{L}, \mathrm{a}^{129} \mathrm{I} /{ }^{127} \mathrm{I}$ ratio higher than $3.5 \times 10^{-11}$ can be determined in $600 \mathrm{~mL}$ water sample using the developed method. For samples with ${ }^{129} \mathrm{I} /{ }^{127} \mathrm{I}$ lower than $3.5 \times 10^{-11}$, a large size sample has to be analyzed. As for seawater, the iodine concentration is normally $45-60 \mu \mathrm{g} / \mathrm{L},{ }^{41}$ which is about two orders of magnitude higher than that in fresh water. Therefore, the developed method can be used to determine a ${ }^{129} \mathrm{I} /{ }^{127} \mathrm{I}$ ratio higher than $5.9 \times 10^{-13}$ in seawater. It is critical to control the amount of the final precipitate $(\mathrm{AgI}-\mathrm{AgCl})$ by partially removal of $\mathrm{AgCl}$ with $\mathrm{NH}_{4} \mathrm{OH}$ rinsing. The variation of ${ }^{127} \mathrm{I}$ ion currents (78$184 \mathrm{nA}$ ) is mainly affected by the final amount of the co- precipitation in addition to the AMS instrument stability in ionization and ion transfer and measurement efficiencies.

Method validation. A certified reference material (IAEA-418) for ${ }^{129}$ I value was analyzed using the developed method. The measured ${ }^{129}$ I concentration of $(24.8 \pm 3.2) \times 10^{7}$ atoms $/ \mathrm{L}$ is in good agreement with the certified value $\left((24.4 \pm 2.7) \times 10^{7}\right.$ atoms $\left./ L\right)$, indicating that the developed method is reliable and accurate for determination of ${ }^{129} \mathrm{I}$ in natural water samples (Table 2).

In additional, the developed method was validated by analysis of five natural water samples collected from China by both the developed co-precipitation method and the conventional solvent extraction method. ${ }^{41,42}$ The concentrations of total ${ }^{129}$ I obtained by two methods are presented in Table 2, which shows a good agreement of ${ }^{129}$ I concentration $(p<0.05)$ between two methods. This confirms that the presented co-precipitation method is reliable and suitable for determination of total ${ }^{129} \mathrm{I}$ in natural water. For lake, river and sea water samples, two aliquots of each sample (e.g. Lake water-1 and Lake water-2) were analyzed, analytical results of ${ }^{129} \mathrm{I}$ in two aliquots samples for these three types of sample agree very well, indicating a very good repeatability of the analytical method.

Determination of ${ }^{129} \mathbf{I}$ in natural water samples. Table 2 shows the analytical results of some natural water samples using the developed method. The ${ }^{129} \mathrm{I}$ concentrations and ${ }^{129} \mathrm{I} /{ }^{127} \mathrm{I}$ ratios in the surface waters (lake water and river water) are (1.6-1.8) $\times 10^{7}$ atoms/L and (4.1-4.5) $\times 10^{-9}$, respectively (Table 2), this is similar to the reported value in a river water from the west of Xi' an ((1.4 $\pm 0.3) \times 10^{7}$ atoms $/ \mathrm{L}$ for ${ }^{129}$ I concentration and $(3.7 \pm 0.6) \times 10^{-9}$ for ${ }^{129} \mathrm{I} /{ }^{127} \mathrm{I}$ ratio). ${ }^{9}$ Meanwhile, the ${ }^{129} \mathrm{I}$ concentration in surface water includes surface sea water is 1-2 orders of magnitudes lower than that contaminated region by human nuclear activities, such as adjacent areas of nuclear fuel reprocessing plants in Europe. .,43 $^{8}$ The measured ${ }^{129} \mathrm{I}$ concentration of rain water collected in 2019 in $\mathrm{Xi}$ ' an $\left(23.0 \times 10^{7}\right.$ atoms/L) falls into the range of the reported ${ }^{129} \mathrm{I}$

Table 2. Analytical Results of Total ${ }^{129} \mathrm{I}$ and ${ }^{127} \mathrm{I}$ in Natural Water Samples Using Co-precipitation and Solvent Extraction for Separation and AMS Measurement $^{\mathrm{a}}$

\begin{tabular}{|c|c|c|c|c|c|}
\hline \multirow{2}{*}{ Sample } & \multirow{2}{*}{${ }^{127} \mathrm{I}(\mu \mathrm{g} / \mathrm{L})$} & \multicolumn{2}{|c|}{${ }^{129} \mathrm{I}$ concentration $\left(\times 10^{7}\right.$ atoms $\left./ \mathrm{L}\right)$} & \multicolumn{2}{|c|}{${ }^{129} \mathbf{I} /{ }^{127} \mathbf{I}$ atomic ratio $\left(\times 10^{-9}\right)$} \\
\hline & & co-precipitation & solvent extraction & co-precipitation & solvent extraction \\
\hline IAEA $418^{\text {b }}$ & $56.6 \pm 1.6$ & $24.8 \pm 3.2$ & $23.3 \pm 1.1$ & $0.92 \pm 0.12$ & $0.87 \pm 0.05$ \\
\hline Lake water-1 & $0.83 \pm 0.01$ & $1.75 \pm 0.05$ & $1.74 \pm 0.05$ & $4.43 \pm 0.13$ & $4.40 \pm 0.14$ \\
\hline Lake water-2 & $0.83 \pm 0.01$ & $1.79 \pm 0.07$ & $1.86 \pm 0.05$ & $4.54 \pm 0.19$ & $4.70 \pm 0.13$ \\
\hline River water-1 & $0.84 \pm 0.01$ & $1.62 \pm 0.06$ & $1.55 \pm 0.04$ & $4.06 \pm 0.16$ & $3.90 \pm 0.12$ \\
\hline River water-2 & $0.84 \pm 0.01$ & $1.66 \pm 0.05$ & $1.63 \pm 0.05$ & $4.17 \pm 0.12$ & $4.09 \pm 0.13$ \\
\hline Rain water & $4.73 \pm 0.05$ & $23.00 \pm 0.32$ & $21.43 \pm 0.28$ & $10.23 \pm 0.18$ & $9.55 \pm 0.16$ \\
\hline Ground water & $2.06 \pm 0.02$ & $0.097 \pm 0.026$ & $0.096 \pm 0.029$ & $0.099 \pm 0.026$ & $0.098 \pm 0.030$ \\
\hline Sea water-1 & $11.0 \pm 0.1$ & $1.45 \pm 0.07$ & $1.59 \pm 0.04$ & $0.28 \pm 0.01$ & $0.31 \pm 0.01$ \\
\hline Sea water-2 & $11.0 \pm 0.1$ & $1.42 \pm 0.14$ & $1.41 \pm 0.04$ & $0.27 \pm 0.03$ & $0.27 \pm 0.01$ \\
\hline
\end{tabular}

${ }^{\mathrm{a}}$ All data presented as average of six measurements; ${ }^{\mathrm{b}}$ The certified value of ${ }^{129} \mathrm{I}$ concentration is $(24.4 \pm 2.7) \times 10^{7}$ atoms $/ \mathrm{L}$. 
concentration collected in the same place from 2008 to 2016 $\left((0.33-152.9) \times 10^{7}\right.$ atoms $\left./ \mathrm{L}\right) .{ }^{44}$ The lowest ${ }^{129} \mathrm{I}$ concentration of $9.7 \times 10^{5}$ atoms $/ \mathrm{L}$ and ${ }^{129} \mathrm{I} /{ }^{127} \mathrm{I}$ ratio of $9.9 \times 10^{-11}$ were measured in the ground water collected from Longxian, China, which is more than one order of magnitude lower than the surface water and two orders of magnitudes lower than the rain water, which indicates that only a small anthropogenic ${ }^{129}$ I from atmospheric deposition entered to this ground water. However, the ${ }^{129} \mathrm{I}$ level in this ground water is significantly higher than the estimated pre-nuclear level of ${ }^{129} \mathrm{I}$ in surface water (approximate $5 \times 10^{4}$ atoms $/ \mathrm{L}$ ), ${ }^{8}$ which might indicate that this shallow ground water has received small fraction of modern meteoric water containing anthropogenic ${ }^{129} \mathrm{I}$, this also shed a light for the application of ${ }^{129} \mathrm{I}$ to trace the source of ground water. The ${ }^{129}$ I concentration $\left(1.4 \times 10^{7}\right.$ atoms $\left./ \mathrm{L}\right)$ in the sea water samples collected in the coast of the East China Sea falls within the reported range of ${ }^{129} \mathrm{I}$ concentration in the East China Sea $\left((0.7-4.0) \quad \times 10^{7}\right.$ atoms/L). ${ }^{10}$ The relatively low ${ }^{127} \mathrm{I}$ concentration in this seawater $(11.0 \mu \mathrm{g} / \mathrm{L})$ compared to the open seawater $(60 \mu \mathrm{g} / \mathrm{L})$ indicates that a large contribution of runoff water (Table 2).

\section{CONCLUSIONS}

A simple and rapid method for separation of iodine from natural water using oxidizing decomposition following $\mathrm{AgI}-\mathrm{AgCl}$ coprecipitation was developed for determination of ultra-low level ${ }^{129}$ I. Digestion with $30 \mathrm{~g} / \mathrm{L} \mathrm{K}_{2} \mathrm{~S}_{2} \mathrm{O}_{8}$ at $\mathrm{pH} 2$ and $60{ }^{\circ} \mathrm{C}$ for $20 \mathrm{~h}$ can effectively release iodine from organic substance in natural waters. A recovery of higher than $90 \%$ for iodine was achieved in this process. Inorganic iodine was successfully separated by coprecipitation of AgI-AgCl- $\mathrm{Ag}_{2} \mathrm{SO}_{3}-\mathrm{Ag}_{2} \mathrm{SO}_{4}$ by addition of $0.5 \mathrm{mg}$ of $\mathrm{Cl}^{-}$and $1 \mathrm{mmol} \mathrm{NaHSO}$ and excessive amount of $\mathrm{AgNO}_{3}$, a recovery of higher than $95 \%$ was obtained for iodine in this step. The addition of small amount of carrier ${ }^{127} \mathrm{I}(0.2 \mathrm{mg})$ can improve the precision of AMS measurement by increasing the stability of the ${ }^{127} \mathrm{I}$ ion current, meanwhile, it limits the contribution of ${ }^{129} \mathrm{I}$ from the ${ }^{127} \mathrm{I}$ carrier and benefits for the determination of ${ }^{129} \mathrm{I}$ in ultra-low-level samples. The detection limit of this developed method for ${ }^{129} \mathrm{I}$ was estimated to be $1.0 \times 10^{5}$ atoms (or $2.2 \times 10^{-17} \mathrm{~g}$ ) for $600 \mathrm{~mL}$ water sample. The method avoids the utilization of toxic organic solvent and suitable for analysis of large batch of samples.

\section{AUTHOR INFORMATION}

\section{Corresponding Author}

*X. L. Hou

Email address: xiho@env.dtu.dk

\section{*Z. Y. Zhang}

Email address: zhangzhy@ihep.ac.cn

Notes

The authors declare no competing financial interest.

\section{ACKNOWLEDGMENTS}

This work was supported by the Key Research Program of the Chinese Academy Sciences (ZDRW-CN-2018-1), Chinese Academy of Sciences (132B61KYSB20180003, XDB40020400), the Ministry of Science and Technology of China (2015FY110800), and the Natural Science Foundation of China (11875261, 91643206).

\section{REFERENCES}

1. G. M. Raisbeck and F. Yiou, Sci. Total Environ., 1999, 237-238, 31-41. https://doi.org/10.1016/S0048-9697(99)00122-9

2. R. R. Edwards, Science, 1962, 137, 851-853. https://doi.org/10.1126/science.137.3533.851

3. J. E. Moran, U. Fehn, and R. T. D. Teng, Chem. Geol., 1998, 152, 193-203. https://doi.org/10.1016/S0009-2541(98)00106-5

4. U. Fehn, J. E. Moran, G. T. Snyder, and Y. Muramatsu, Nucl. Instrum. Meth. B., 2007, 259, 496-502. https://doi.org/10.1016/j.nimb.2007.01.191

5. X. Hou, V. Hansen, A. Aldahan, G. Possnert, O. Lind, and G. Lujaniene, Anal. Chim. Acta, 2009a, 632, 181-196. https://doi.org/10.1016/j.aca.2008.11.013

6. P. Yi, X. G. Chen, D. X. Bao, R. Z. Qian, A. Aldahan, F. Y. Tian, ... and B. Wang, Appl. Radiat. Isot., 2013, 82, 223-231. https://doi.org/10.1016/j.apradiso.2013.07.034

7. X. Hou, A. Aldahan, S. P. Nielsen, and G. Possnert, Environ. Sci. Technol., 2009b, 43, 6522-6528. https://doi.org/10.1021/es9012678

8. G. Snyder, A. Aldahan, and G. Possnert, Geochem. Geophys. Geosyst., 2010, 11, Q04010/1-19. https://doi.org/10.1029/2009GC002910

9. L. Zhang, W. Zhou, X. Hou, N. Chen, Q. Liu, C. He, Y. Fan, M. Luo, Z. Wang, and Y. Fu, Sci. Total Environ., 2011, 409, 37803788. https://doi.org/10.1016/j.scitotenv.2011.06.007

10. D. Liu, X. Hou, J. Du, L. Zhang, and W. Zhou, Sci. Rep., 2016, 6, 36611. https://doi.org/10.1038/srep36611

11. X. Zhao, X. Hou, J. Du, and Y. Fan, Environ. Pollut., 2019, 245, 443-452. https://doi.org/10.1016/j.envpol.2018.11.018

12. U. Fehn, G. Snyder, and P. K. Egeberg, Science, 2000, 289, 2332-2335. https://doi.org/10.1126/science.289.5488.2332

13. X. Hou, P. P. Povinec, L. Zhang, K. Shi, D. Biddulph, C.-C. Chang, Y. Fan, R. Golser, Y. Hou, M. Jeskovsky, A. J. T. Jull, Q. Liu, M. Luo, P. Steier, and W. Zhou, Environ. Sci. Technol., 2013, 47, 3091-3098. https://doi.org/10.1021/es304460k

14. F. Álvarez, M. Reich, G. Snyder, A. Pérez-Fodich, Y. Muramatsu, L. Daniele, and U. Fehn, Appl. Geochem., 2016, 68, 53-63. https://doi.org/10.1016/j.apgeochem.2016.03.011 
15. S. P. V. Tan, A. T. Bautista, N. D. S. Mendoza, C. D. T. Racadio, M. Puthenpurekal, A. C. Resurreccion, and H. Matsuzaki, J. Environ. Radioact., 2020, 218, 106239. https://doi.org/10.1016/j.jenvrad.2020.106239

16. G. Klevinskas, L. Juodis, A. Plukis, R. Plukiene, and V. Remeikis, Nucl. Eng. Des., 2008, 238, 1518-1524. https://doi.org/10.1016/j.nucengdes.2007.10.012

17. J. M. López-Gutiérrez, H. A. Synal, M. Suter, C. Schnabel, and M. García-León, Appl. Radiat. Isot. 2000, 53, 81-85. https://doi.org/10.1016/S0969-8043(00)00116-0

18. X. Hou, H. Dahlgaard, B. Rietz, P. Jacobsen, S. Nielsen, and A. Aarkrog, Analyst, 1999, 124, 1109-1114. https://doi.org/10.1039/a902373i

19. K. Nishiizumi, D. Elmore, M. Honda, J. R. Arnold, and H. E. Gove, Nature, 1983, 305, 611-612. https://doi.org/10.1038/305611a0

20. U. Rao and U. Fehn, Geochim. Cosmochim. Acta, 1999, 63, 1927-1938. https://doi.org/10.1016/S0016-7037(99)00133-7

21. N. Buraglio, A. Aldahan, and G. Possnert, Nucl. Instrum. Meth. B., 2000, 161, 240-244. https://doi.org/10.1016/S0168-583X(99)00749-1

22. J. E. Moran, U. Fehn, and J. S. Hanor, Geochim. Cosmochim. Acta, 1995, 59, 5055-5069. https://doi.org/10.1016/0016-7037(95)00360-6

23. H. Reithmeier, V. Lazarev, F. Kubo, W. Rühm, and E. Nolte, Nucl. Instrum. Meth. B., 2005, 239, 273-280. https://doi.org/10.1016/j.nimb.2005.04.070

24. Q. Liu, X. Hou, W. Zhou, and Y. Fu. J. Am. Soc. Mass Spectrom., 2015, 26, 725-733. https://doi.org/10.1021/jasms.8b05022

25. X. Hou, W. Zhou, N. Chen, L. Zhang, Q. Liu, M. Luo, Y. Fan, W. Liang, Y. Fu, Anal. Chem., 2010, 82, 7713-7721. https://doi.org/10.1021/ac101558k

26. L. Zhang, X. Hou, W. Zhou, N. Chen, Q. Liu, M. Luo, Y. Fan, and Y. Fu, Nucl. Instrum. Meth. B., 2013, 294, 276-280. https://doi.org/10.1016/j.nimb.2012.06.023

27. M. Luo, X. Hou, C. He, Q. Liu, and Y. Fan, Anal. chem., 2013, 85, 3715-3722. https://doi.org/10.1021/ac400060q

28. H. Dang, X. Hou, P. Roos, and S. P. Nielsen, Anal. Meth., 2013, 5, 449-456. https://doi.org/10.1039/c2ay25958c

29. W. Zhou, N. Chen, X. Hou, L. Zhang, Q. Liu, C. He, Y. Fan, M. Luo, Y. Zhao, and Z. Wang. Nucl. Instrum. Meth. B., 2013, 294, 147-151. https://doi.org/10.1016/j.nimb.2012.07.044
30. K. A. Schwehr, P. H. Santschi, and D. Elmore, Limnol. Oceanogr. Meth., 2005, 3, 326-337. https://doi.org/10.4319/lom.2005.3.326

31. B. S. Gilfedder, S. C. Lai, M. Petri, H. Biester, and T. Hoffmann, Atmos. Chem. Phys., 2008, 8, 6069-6084. https://doi.org/10.5194/acp-8-6069-2008

32. K.-C. Huang, Z. Zhao, G. E. Hoag, A. Dahmani, and P. A. Block, Chemosphere, 2005, 61, 551-560. https://doi.org/10.1016/j.chemosphere.2005.02.032.

33. S. Guchhait, M. Banerjee, and R. S. Konar, J. Appl. Polym. Sci., 1991, 43, 757-765. https://doi.org/10.1002/app.1991.070430413

34. N. M. Beylerian, L. R. Vardanyan, R. S. Harutyunyan, and R. L. Vardanyan, Macromol. Chem. Phys., 2002, 203, 212-218. https://doi.org/10.1002/1521-3935(20020101)203:1<212::AIDMACP212>3.0.CO;2-3

35. G. R. Peyton, Mar. Chem., 1993, 41, 91-103. https://doi.org/10.1016/0304-4203(93)90108-Z

36. S. G. Huling, S. Ko, and B. Pivetz, Groundwater Monit. Rem., 2011, 31, 72-79. https://doi.org/10.1111/j.1745-6592.2011.01332.x

37. D. C. Kocher, Environ. Int., 1981, 5, 15-31. https://doi.org/10.1016/0160-4120(81)90110-0

38. W. R. Kelly, S. V. Panno, K. C. Hackley, H. H. Hwang, A. T. Martinsek, and M. Markus, Appl. Geochem., 2010, 25, 661673. https://doi.org/10.1016/j.apgeochem.2010.01.020

39. W. Stumm and J.J. Morgan, Aquatic chemistry, chemical equilibria and rates in natural waters. New York, Third ed. John Wiley \& Sons, Inc., 1996.

40. S. Xing, X. Hou, A. Aldahan, and G. Possnert, J. Radioanal. Nucl. Chem., 2017, 311, 833-841. https://doi.org/10.1007/s10967-016-5060-6

41. X. Hou, A. Aldahan, S. P. Nielsen, G. Possnert, H. Nies, and J. Hedfors, Environ. Sci. Technol., 2007, 41, 5993-5999. https://doi.org/10.1021/es070575x

42. X. Hou, H. Dahlgaard, and S. P. Nielsen, Mar. Chem., 2001, 74, 145-155. https://doi.org/10.1016/S0304-4203(01)00010-X

43. A. M. Wefing, M. Christl, C. Vockenhuber, M. Rutgers van der Loeff, and N. Casacuberta, J. Geophys. Res.: Oceans, 2019, 124, 882-896. https://doi.org/10.1029/2018JC014399

44. X. Jiang, A study on the level and variation of ${ }^{129} \mathrm{I}$ in precipitation in Xi'an region and its application as environmental tracer. Xi'an, Institute of Earth Environment, CAS, 2017. 